\title{
Dealing with heritage Hanoi Old Quarter
}

\author{
Dung Ngo Thi Kim* \\ Hanoi Architectural University, Viet Nam
}

\begin{abstract}
Properly solving the relationship between conservation and devel-opment is one of the important requirements in the development of historic urban. The author approaches the issue through case studies of the old Quarter, a special historical sites of Hanoi capi-tal. The process of urbanization and urban development has af-fected and made Hanoi Old Quarter (HOQ) many changes. How to maintain HOQ has been studied by many scientists. Some of the results of those studies have been applied in practice. Howev-er, the results are still moderate. This study focuses on compre-hensive review of the features of HOQ and its transformation in both tangible and intangible aspects. The author used the field survey method and secondary data for research. The results of the study have shown the characteristics of HOQ along with its changes in the aspects of economy, culture, society, science-technology and architecture-planning. The current status of HOQ is: Population density is too high; altered traditional functions; space, architecture and landscape are deformed and its characteristic elements are gradually lost; polluted environment, technical infrastructure are overloaded. The article al-so discusses the direction to maintain and develop HOQ as a his-torical sites without hindering the development of smart and sus-tainable urban development..
\end{abstract}

\section{Introduction}

Hanoi Old Quarter (HOQ) was formed during the Ly dynasty (1009 - 1225). By the end of the 17th century, this area had developed into a bustling and beautiful shopping mall on the banks of the Red River [1]. HOQ has many changes together with the development of economics, society, and urbanization for the past 1,000 years. Currently, this area covers an area of about 82 hectares, including 10 wards, located in Hoan Kiem district, Hanoi. This is the place containing a diverse and attractive tangible and intangible value treasure. The main functions of HOQ are commerce, services, and housing. Having the unique values of the urban spatial structure associated with the trade streets, trade wards, traditional festivals and the system of historical and architectural relics, HOQ has been recognized as a national historical relic in 2004 [2]. In the process of urban development, the values of HOQ are in danger of fading due to a variety of subjective and objective reasons [3]. The characteristics of HOQ also gradually changed [4]. Therefore, how to deal with the HOQ in order to preserve its unique values while still ensuring the living needs of residential communities and urban development goals is an urgent issue. Much research has been done. The Institute

\footnotetext{
* Corresponding author: dungnkhau@gmail.com
} 
of Rural Urban Planning, the Ministry of Construction (1993) has provided orientation towards conservation levels, conservation and improvement of HOQ; Professor Pham Dinh Viet also mentioned reducing population density and improving living environment (1995); Hanoi city and Toulouse city have coordinated research to renovate a number of monuments, embellish streets and preserve traditional trades; Doctoral thesis of the authors: To Kien [5], Dao Thi Nhu [6] did research on HOQ and heritage architecture in HOQ. Overall, most of the studies have been done long ago. As a result, a large amount of data is no longer updated. The content of these studies often focuses on analyzing heritage values, providing technical solutions to preserve specific objects such as tube houses, streets, blocks, or in-depth research on one or more some elements of the HOQ that have not yet been approached HOQ holistically from many aspects. The author wants to learn about the current state of HOQ through consideration of its characteristics and variation in all related aspects such as economics, culture, society, science, technology, architecture and planning. On that basis, the author will discuss the direction to maintain and develop HOQ as a historical sites without hindering the development of smart and sustainable urban.

Research question:

- What are the characteristics features of HOQ? How have those characteristics changed?

- Which elements of HOQ are taken into consideration by professionals, managers, local residents and tourists?

- Which elements of the HOQ need to be preserved and how?

\section{Methodologies and Data}

The author uses qualitative analysis based on 2 types of data. Secondary data is collected from published reports, studies, statistics, documents. Primary data is collected directly by the author using in-depth interviews and observations. For local residents and tourists, a structured interview format is used (Predefined topics and questions, respondents have the same questions). For professionals and managers, an unstructured interview is used in both direct and indirect forms. Together with the interview, the author implemented the observational method to find out research problems and verify the secondary data.

\section{Research results}

\subsection{Characteristics of HOQ and its changes}

\subsubsection{Social and economic characteristics}

a. Population and housing. According to the census of 2019, HOQ has approximately 70,000 people and 4,989 house numbers. Each house has an average area of about $92 \mathrm{~m} 2$ in which three to five or even 10 households live. The living area is only $0.5-1.8 \mathrm{~m} 2 /$ person. The population density here is up to 823 people/ha. Summarising survey data shows that the quality of housing, sanitary conditions and living area are supposed to be poor and extremely poor with the rates of $54 \%, 63 \%$ and $74 \%$ respectively.

Table 1. Residents' opinions on current living conditions in Hanoi Old Quarter. [Source: The author summarised from the survey results, 2020]

\begin{tabular}{ccccc}
\hline Content & Good (\%) & Average (\%) & Poor (\%) & Too bad (\%) \\
\hline Housing quality & 3 & 41 & 32 & 24 \\
Living area & 0 & 26 & 46 & 28 \\
Sanitary and environmental & 14 & 23 & 37 & 26
\end{tabular}




\begin{tabular}{ccccc}
\hline Content & Good (\%) & Average (\%) & Poor (\%) & Too bad (\%) \\
\hline Landscape architecture & 25 & 39 & 27 & 09 \\
\hline
\end{tabular}

b. Commercial activities. Initially, residents in HOQ mainly worked in handicrafts and did small business in the form of guilds. Housing is a place to live, produce and do business. Each street sells one type of product [7]. During the French colonial period, there were about 20 streets specializing in buying and selling goods; 63 streets both produce goods and buy and sell goods [8]. Currently, only 3 streets (accounting for 3.79\%) trade in traditional goods, namely Hang Ma, Hang Day and Hang Manh; 6 streets still maintain traditional handicrafts (accounting for 7.59\%). Individual business model has replaced enterprise form as before. Business types are also more diversified Business subjects here are not only residents of HOQ but also people from elsewhere. another to rent a site [2].

Table 2. Commercial activities in Hanoi Old Quarter in the past and at present. [Source: Summarised by the author from sources 2,8]

\begin{tabular}{ccc}
\hline & In the past & At present \\
\hline Activities & Production, trade & Production, trade, service \\
Scope & Areas exposed to the street & Areas exposed to the street, first floor, part of the \\
& and part of the first floor & upper floors, or the entire house \\
Agent & HOQ Residents & HOQ Residents, residents of other \\
Customers & Local residents & Local residents, tourists \\
\hline
\end{tabular}

The space for commercial activities in each house also changes in the direction of further expansion. Many owners have moved to other places intending to use the entire house for business purposes.
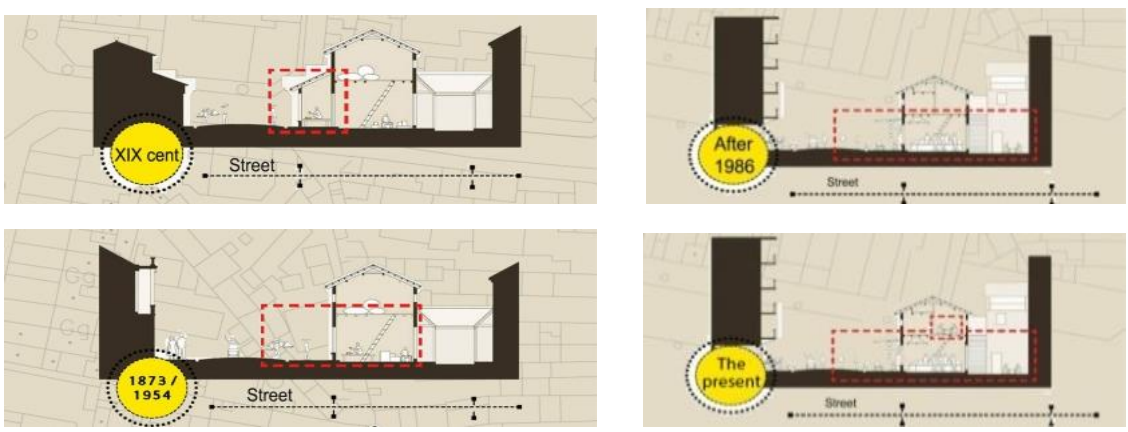

Fig. 1. Commercial spaces of tube houses in the Old Quater. [Source: 2]

\subsubsection{Spatial Structural characteristics}

HOQ is a typical urban structural of an old urban. Initially, it was a trade ward and then developed into cities and blocks. Streets connect many wards into a street network [9]. a. Street network. A very narrow and short street network in HOQ mainly serves pedestrians and rudimentary vehicles. Currently, HOQ has 79 streets with a road density of $16 \mathrm{~km} / \mathrm{km} 2$. The street network almost remains unchanged from the previous century.

Table 3. Size of the streets in HOQ. [Source: 2]

\begin{tabular}{ccc}
\hline Street width (m) & Quantity (Streets) & Pavement \\
\hline$\geq 20$ & 5 & Yes \\
From 15-19 & 34 & Yes \\
From 10-14 & 32 & Yes \\
$<10$ & 8 & Yes or No \\
\hline
\end{tabular}


b. Block and plot. Hanoi Old Quarter has a particularly unique structure. The streets are intersecting one another other creating 83 blocks which are not even in terms of shape and area. At present, the number and size of the block are still preserved. However, the structure has been changed dramatically compared to the one in the past due to the increase of the solid block space and the reduction of the empty space. The land plots in Hanoi Old Quarter have a particularly typical shape, the length is often many times larger than the width. [2]

c. Construction works. The architecture in HOQ is a combination of many traditional and modern styles of Vietnam, China, Europe but basically unified in terms of the rhythm and shape [10]. There are 120 Public buildings as monuments. Religious works basically remains architectural styles but have the signs of being encroached, being dominated in terms of space, technically deteriorating and changing functional uses. Cultural and artistic works such as San nhien dai theater, Quang Lac theater, A dao theater establishments on Hang Giay street have been turned into houses and used for other functions. The remaining Public buildings are all small-scale and have no special values [2]. Housing is the main type of architecture in HOQ. Of all the Residential buildings constructed before 1954, 553 of those are considered to be valuable. The remaining buildings no longer have typical characteristics due to having been repaired many times [11]. Most of it were built into tube houses which many layers and separated by courtyards. In particular, about $30 \%$ of houses are 15 to $30 \mathrm{~m}$ long; $40 \%$ are $30-45 \mathrm{~m}$ long; $20 \%$ are over $50 \mathrm{~m}$ long; $10 \%$ have different sizes [12]. Some typical architectural styles of houses at HOQ are: Traditional architecturalstyle, Chinese architectural style, European architectural style [2], [13], [14].

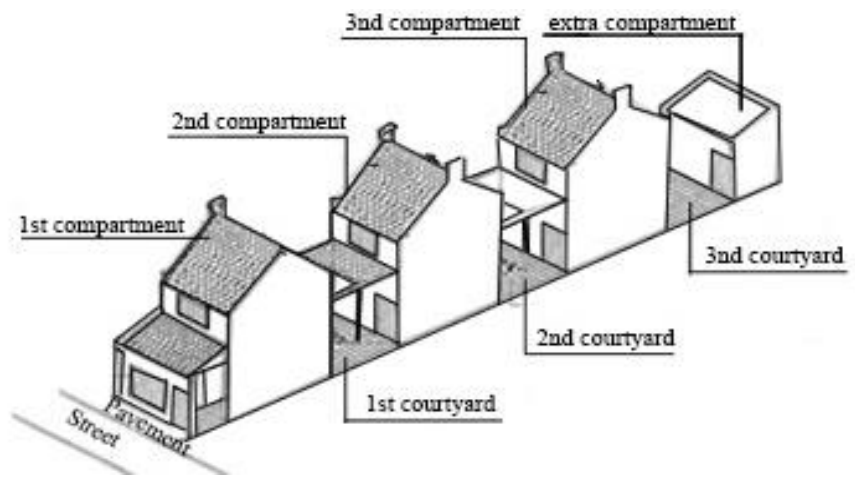

Fig. 2. Structure of tube house in HOQ. [Source: 6]

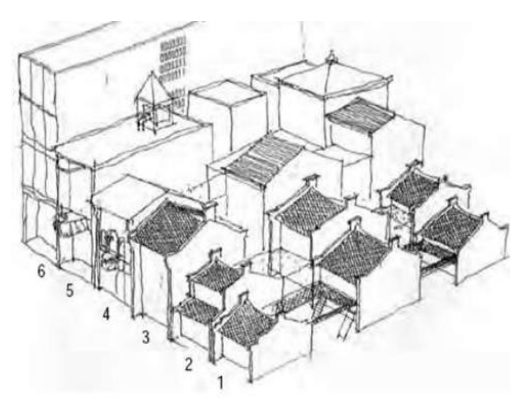

\section{Before 1802}

2. Between 1802-1873 (Pre-colonial)

3. Tube house with the floor (not popular before 1873), popular in the colonial period

4. Period between 1873-1954

5. Modern tube house (not popular before 1992, popular after the Renovation)

6. Contemporary tube-house popular after 1992

Fig. 3. Changes of tube houses in Hanoi Old Quarter through different stages. [Source: 6]

d. Empty space. HOQ has almost no playgrounds, flower gardens, squares. Only Duong Thanh flower garden with an area of $990 \mathrm{~m} 2$ is located at the border of HOQ in Cua Dong ward. Empty spaces, green spaces, gardens in houses and streets have also been 
transformed into other living spaces. Currently, only $27 / 83$ city blocks still have empty yards. The construction density is too high (mostly over $90 \%$ ), has provided the city blocks with extremely poor ventilation. [Documentation of HOQ Management Board and author's verification].
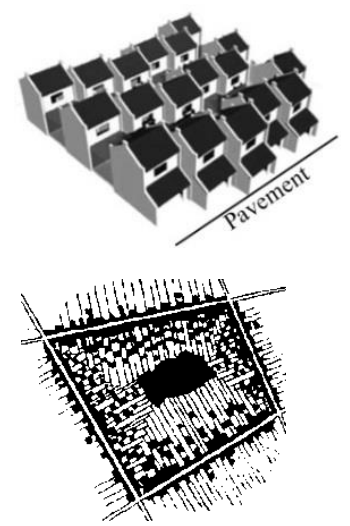
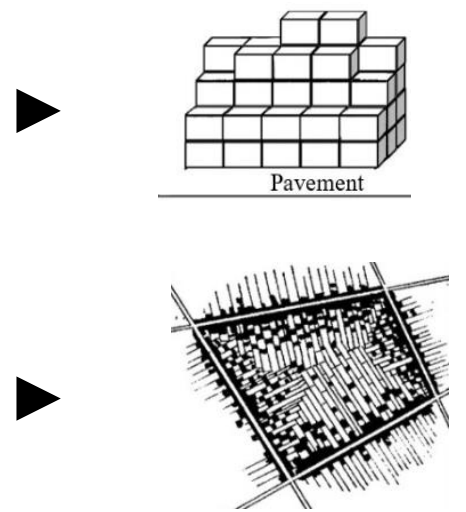

Fig. 4. Changes of empty space in Tube houses and blocks [Source: 2,5]

\subsubsection{Landscape}

The landscape of HOQ is the convergence of many factors such as old architectural works with typical shapes and styles, green trees, and especially the street landscape. Currently, the landscape in HOQ is changing for the worse. The street facade is messy and patchy. The spatial envelope of the street is broken. The architectural form of traditional houses is deformed, due to the time and repair and expansion activities of the people. Facades of houses are obscured by goods and billboards. Sidewalks are occupied as a place for sales and parking. Newly built houses have a hybrid form, not suitable for the whole area. The public lighting system, electric poles, billboards, mobile canopies are not designed appropriately, affecting the street's aesthetic. The network of trees and flower gardens is inadequate and the urban environment is polluted [4].

\subsection{People's opinion about $\mathrm{HOQ}$}

\subsubsection{Residents living in the $H O Q$}

The author has randomly selected 250 house numbers on 42 streets $(50.6 \%)$ for the survey. Respondents could be the host or members 18 years of age or older.

Content 1: Do you want to move to another place to live?; Result: $17 \%$ want to move to another place, $12 \%$ do not want to move to another place and $71 \%$ want to live in old location but are allowed to upgrade and renovate their houses according to their needs.

Content 2: If you do not want to move, what is the reason? (Questions with many options).

Results: Due to habit (17\%), do not want to leave the place of birth and grow up (34\%), HOQ is the main source of income for the family (63\%) and HOQ is the ideal place ( $55 \%)$

Content 3: What do you expect from HOQ conservation? (The question has many options).

Results: Improve the living environment (92\%); Increase living area (72\%); Allowed to renovate and upgrade houses (55\%); Increase job opportunities and income (76\%); Restore and develop traditional cultural values (44\%). 
Content 4: How is the suitability and effectiveness of policies and solutions applied in HOQ? Results: Table 4.

Summarizing survey data shows that: The majority of people currently living in HOQ do not want to move to other places to live; The most important reason is that HOQ creates the main source of income for the family; The biggest desire of the people is that their living environment is improved; Solutions and policies to be applied in HOQ are assessed by experts and people at medium and low level.

Table 4. Effectiveness and suitability of policies and solutions applied in HOQ.

\begin{tabular}{ccccccc}
\hline \multirow{2}{*}{ Policy, solution } & \multicolumn{3}{c}{ Appropriateness (\%) } & \multicolumn{3}{c}{ Effective (\%) } \\
\cline { 2 - 7 } & $\begin{array}{c}\text { Approp } \\
\text {-riate }\end{array}$ & $\begin{array}{c}\text { Quite } \\
\text { Appropriat } \\
\text { e }\end{array}$ & $\begin{array}{c}\text { Not } \\
\text { Appropri } \\
\text { ate }\end{array}$ & $\begin{array}{c}\text { Goo } \\
\text { d }\end{array}$ & $\begin{array}{c}\text { Averag } \\
\text { e }\end{array}$ & Poor \\
\hline Planning, architecture & 23 & 36 & 51 & 21 & 33 & 46 \\
Commercial activities & 52 & 34 & 24 & 61 & 27 & 12 \\
People's relaxation policy & 13 & 32 & 55 & 9 & 25 & 66 \\
Policies to support people & 37 & 44 & 19 & 42 & 38 & 20 \\
\hline
\end{tabular}

\subsubsection{Tourists}

For this group, the author randomly selects tourists from HOQ or through travel agencies. The survey time was according to four seasons of the year.

Content 5: What is the reason for visiting HOQ ? Result: curiosity $(23 \%)$, due to the popularity of the HOQ $(66.3 \%)$ and a mandatory activity of the tourist itinerary $(10.7 \%)$.

Content 6: Which elements of HOQ do you like? Results: Architecture (38\%), landscape (47\%), cuisine (61\%), people (58\%), services (54\%) and goods (44\%).

Survey results show that most tourists visit HOQ because it is a famous place. The factors that are loved by tourists don't differ too much; However, the element of landscape architecture is not appreciated.

\subsubsection{Experts and managers}

For this group, the author collects opinions directly and indirectly. The results showed that experts and managers agreed to recognize the values of HOQ as an important factor to identify the urban cultural identity of Hanoi. Restoring, preserving and promoting the values of the heritage HOQ is a very difficult task. It requires the cooperation of many disciplines . With the content "Which elements of Hanoi Old Quarter need to be preserved and how to preserve ?", the answers are: Reduce population density (98\%); maintain the structure and spatial morphology of HOQ (87\%); preserving valuable architectural works and historical sites and cultural monuments $(85.3 \%)$; preserving the traditional handicraft streets $(34.6 \%)$; preserving the traditional functions of HOQ $(43.2 \%)$. The vast majority of solutions focus on maintaining HOQ in a physical environment.

\section{Discussion}

\subsection{Purpose}

In order to meet the requirements of sustainable development, the conservation of HOQ must be balanced between the objectives in the following priority order: (1) Ensuring 
living, working and and income for people living in HOQ; (2) Maintaining HOQ as an important and special urban heritage; (3) Not hindering local economic and social development.

\subsection{The elements of $H O Q$ need to be preserved}

HOQ is a particularly important historical sites that needs to be preserved, but it is also inhabited by a residential community and the economic and cultural center of the capital. Preserving HOQ as a museum is difficult and inappropriate. Therefore, the choice of content and solutions for conservation of HOQ should be considered on the basis of science and practice. According to the author, the core factors of HOQ that needs to maintain is the landscape, identifiable characteristics and cultural identity of the region. Detail:

- Material factors: Need to preserve the overall space of HOQ with five basic elements: Street network, block, a parcel of land, valuable architectural works, empty space (garden, yard, square) and natural landscape.

- Non-material factors: It is necessary to restore and maintain the cultural activities typical of HOQ such as streets with traditional crafts; street name associated with the products it produces and trades; spiritual culture; culture and arts; festival culture and culinary culture. The remaining factors allow adjustment to adapt to current life needs.

\subsection{Orientation to maintain and develop HOQ}

The contents analysed in part 3 show us that maintaining the heritage but ensuring living conditions for people and developing the local economy is very difficult and complicated. Therefore, there should be an overall strategy to preserve the HOQ heritage.

\subsubsection{Economic aspect}

HOQ plays an important role in the economic development of Hanoi capital. Therefore, conservation HOQ is an integral part of local economic development policies. There is a need to develop policies and regulations for the types of goods, business forms and services in HOQ. Currently, along with 3 streets selling the same products as the street names, HOQ has 6 streets that also work with traditional handicrafts and 17/79 streets that sell the same items as before in small quantities. The government needs to support mechanisms, policies and finance to maintain and restore job streets as before. Streets which used to do business in goods which are no longer suitable for the demands of our contemporary society such as (Hang Bong, Hang Gai, Hang Be, Hang Can, Hang Chai, Hang Chinh, Hang Cot, Hang Dieu, Hang Phen) are allowed to change business modes and types of goods. For the remaining streets, it is possible to adjust business practices to suit the development requirements of the area. Accommodation, dining, massage, and karaoke services must be arranged at the edge of HOQ and core areas of the blocks so as not to affect the traditional landscape.

\subsubsection{In terms of culture and society}

It is best to implement the population expansion policy to reduce the population density to asymptotic to the average population density of inner Hanoi. But it requires detailed plans and approach appropriate with each group. Ensuring the minimum living area from $20 \mathrm{~m} 2$ to $25 \mathrm{~m} 2$ per person should be taken into account. Also, it is essential to develop appropriate management policies for people from other places renting a place in HOQ to do 
business. It is advisable to organize extra walking streets in flexible ways (full time, some hours/day, or some days/week). Need enhance green means of transport such as cyclo and tram to serving tourists and reducing environmental pollution; to restore some sites of traditional cultural and artistic activities in HOQ such as San nhien dai theater for Cheo singing, Quang Lac theater for Cai luong singing, A dao singing; organizing performance spaces and mobile playgrounds for festival activities, performing arts, traditional folk games and culinary fairs.

\subsubsection{In terms of planning, architecture, landscape}

Population growth, changes in people's lifestyles and business activities in HOQ inevitably lead to the change of functional spaces, structures and architectural works of the urban. Therefore, there should be a careful consideration.

a. Planning. The detailed planning should meet the following requirements: Preserves the overall space of the HOQ; Preserving the area and shape of the block and land plots (It is possible to merge and split plots to increase efficiency but separate elements must be maintained outside of the works); maintaining the street network; Improving, restoring and expanding core areas of the blocks to increase green space and empty space; Adjust the height and volume of the building, but restore and maintain open spaces between compartments to ensure sanitary and environmental conditions.

Table 5. Preservation model of HOQ. [Source: Edited by the author]

\begin{tabular}{ccc}
\hline Area. & Solution & Illustration \\
\hline $\begin{array}{c}\text { Protected } \\
\text { area level 1 }\end{array}$ & $\begin{array}{c}\text { To preserve and restore the outer layer of a block adjacent to } \\
\text { four street surfaces (1). Restore, renovate, and adapt the core of } \\
\text { the block according to the old structure, area (2). }\end{array}$ \\
$\begin{array}{c}\text { Protected } \\
\text { area level 2 }\end{array}$ & $\begin{array}{c}\text { Embellish the outer layer of the block adjacent to the four street } \\
\text { surfaces (3). Conservation and restoration of works of special } \\
\text { value (4). It can renovate and build new houses from the 2nd } \\
\text { layer inside according to the appropriate height and volume } \\
\text { limits (5). }\end{array}$ \\
\hline
\end{tabular}

b. Architecture. Management organizations need to select several Tube houses with typical values to preserve, embellish or restore according to the traditional architectural structure, form, and style. These houses can be places to visit or business accommodation services in the form of Homestay for visitors to experience in the space of the last century.

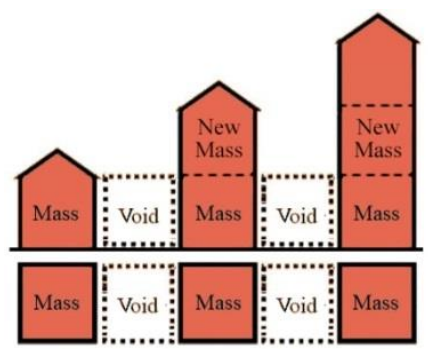

(a) Grow Height

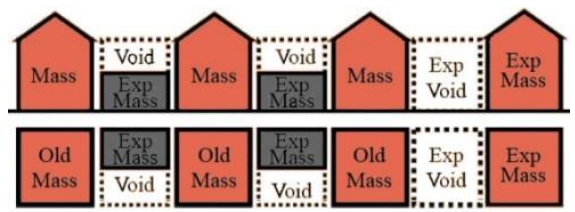

(b) Grow Width

Fig. 5. Diagram of renovation and expansion of the tube houses [Source: Edited by the author] 
The remaining Tube houses allow owners to renovate, upgrade and expand the space according to the options: Height (a) or width (b) development ( Figuge 5). For monuments that need to be protected according to the Law on Cultural Heritage 2013. For other works, it is necessary to base on the value, characteristics and type of works to apply the appropriate content and form of intervention (Table 6).

Table 6. Forms of interventions for buildings in HOQ [Source: Edited by the author]

\begin{tabular}{cc}
\hline Status & Content, the form of intervention \\
\hline Lost & Restoration \\
Some parts are lost & Reconstruction and supplementation \\
Modified & Re-adjust \\
Broken, degraded & Restoration and embellishment \\
\hline
\end{tabular}

c. Landscape. Special attention should be paid to the embellishment of street landscapes (sidewalks, trees, facade of buildings adjacent to the street and billboards; Landscape restoration and development of monument sites to increase green space for the urban; Need to have a separate urban design project suitable to the characteristics of HOQ. Note elements (electric wires, poles, telecommunication cables, lighting systems)

\subsubsection{In terms of science and technology}

Currently, the preservation of HOQ in physical environment is really difficult. But the achievements of Industry 4.0 will help us to solve this problem. We can approach new ways of doing things in parallel with traditional methods to achieve the goal of harmonious combination of sustainable conservation with exploitation and promotion of the resources of heritage and monuments. One notable solution is Heritage Conservation, monuments in a digital environment (Virtual).

Table 7. Preservation of HOQ in a virtual environment [Source: Summarised by the author]

\begin{tabular}{|c|c|c|}
\hline Work content & Technology, Solutions & $\begin{array}{l}\text { Subjects of } \\
\text { application }\end{array}$ \\
\hline $\begin{array}{l}\text { Digitize the tangible and intangible } \\
\text { elements of heritage and relics. }\end{array}$ & $\begin{array}{l}\text { 3D scan, Virtual reality, Mixed } \\
\text { reality (MR) technology. }\end{array}$ & $\begin{array}{l}\text { The entire Old Quarter, } \\
\text { typical buildings, } \\
\text { intangible elements. }\end{array}$ \\
\hline $\begin{array}{l}\text { Construction reconstruction, } \\
\text { construction parts. }\end{array}$ & Artificial Intelligence, LASER & $\begin{array}{c}\text { The work or } \\
\text { construction part with }\end{array}$ \\
\hline $\begin{array}{l}\text { Detect structure damage. } \\
\text { Determining methods and materials to } \\
\text { preserve and restore relics. }\end{array}$ & CLOUD software. & $\begin{array}{l}\text { characteristic value has } \\
\text { been lost or damaged. }\end{array}$ \\
\hline Introduction and promotion of heritage. & $\begin{array}{c}\text { Virtual reality }(\mathrm{VR}) \text {, Augmented } \\
\text { reality }(\mathrm{AR}), \text { Mixed Reality } \\
(\mathrm{MR}) \text { technology }\end{array}$ & $\begin{array}{l}\text { Management, } \\
\text { exploitation, and use of } \\
\text { relics. }\end{array}$ \\
\hline $\begin{array}{l}\text { Develop an online tour. } \\
\text { Create virtual space, recreate historical } \\
\text { scenes of heritage. }\end{array}$ & $\begin{array}{l}\text { VR, AR technology, sound } \\
\text { technology (Dollthy Atmos) } \\
\text { technology, Photoshop, Finalcut } \\
\text { software and assistive devices } \\
\text { (VR glasses, headphone), output } \\
\text { device ( Smartphone, tablets) }\end{array}$ & $\begin{array}{l}\text { Exploitation of relics } \\
\text { and tourists. }\end{array}$ \\
\hline $\begin{array}{l}\text { Build smart interactive maps, digital } \\
\text { maps with properties: location, } \\
\text { number, plot area, current housing } \\
\text { status, number of households, number } \\
\text { of people, repair, construction, } \\
\text { construction relics. }\end{array}$ & $\begin{array}{l}\text { BIM, GIS, MAP GIS technology } \\
\text { and assistive devices: GPS, LBS, } \\
\text { UAV, 3D scan, Mapinfo, IOT. }\end{array}$ & $\begin{array}{l}\text { Archives and } \\
\text { management of } \\
\text { heritage and tourists. }\end{array}$ \\
\hline
\end{tabular}


With the support of modern science and technology, urban areas in general and HOQ heritage in particular have the opportunity to exist sustainably in a simulated environment. However, implementing this solution requires a large amount of money and the acceptance of experts and the community.

\section{Conclusion}

After researching, the author concludes: HOQ is a valuable urban heritage that needs to be maintained; Over time, HOQ's social characteristics (population size, residence density, occupation structure, economic structure, lifestyle, living habits of the people) have been changing. Accordingly, the architectural space and landscape of HOQ also change. The author said that the preservation of HOQ is very necessary; the relationship between heritage conservation and urban development must be properly addressed; the physical and intangible elements need to be preserved in parallel. Based on the research results, the author mentioned some directions to preserve Hanoi Old Quarter from economic, cultural - social, planning architectural, and science - technology aspects. In which, the author emphasizes that conserving HOQ in a virtual environment is a solution that needs to be studied and applied in current practical conditions. That can be one of the suitable solutions to maintain urban heritage such as HOQ in terms of smart and sustainable urban development.

\section{References}

1. M. Nguyen, The socio-economic development of HOQ, Architectural Journal, Vietnam Association of Architects 4 (2018)

2. HOQ Management Board

3. A. Nguyen, Current situation and solutions to improve the quality of space and landscape architecture in HOQ. Planning HOQ with planning of Hanoi capital, in Proceeding of the conferense Preserve, embellish and promote the heritage value of HOQ, pp. 20-24 Hanoi (2020)

4. H. Ta, L. Pham, N. G. Nguyen, An assessment of street space landscape in HOQ to establish a guiding framework for urban design of street space and to restore street features, Scientific research subject of the Construction university (2006)

5. K. To, "Tube House" and "Neo Tube House" in Hanoi: A Comparative Study on Identity and Typology, Journal of Asian Architecture and Building Engineering 4 (2008)

6. N. H. Dao, Urban architectural heritage preservation in Hanoi: The community's participation, Doctoral Thesis, Université Panthéon-Sorbonne - Paris I, pp.157 (2017)

7. H. Nguyen, Organizing architectural space for handicraft production and trading area in $H O Q$, Doctoral Thesis, Hanoi Architectural University (2002)

8. D. Nguyen, City, ward and people of Hanoi In history, Cultural and Information Publishing House (1999)

9. B. Dang, Sustainable conservation of $H O Q$, in Proceeding of the Conferense Preserve, embellish and promote the heritage value of HOQ, pp. 33-38 Hanoi (2020)

10. N. H. Dao, HOQ in the development process of Thang Long-Hanoi, in Proceeding of the Conferense Preserve, embellish and promote the heritage value of HOQ, pp. 86-89, (2020)

11. HOQ Management Board, Regulation on planning and architectural management of $H O Q(2013)$

12. V. Pham, Talking about tube house in $H O Q$, Vietnam architecture Journal 8 (2006)

13. N. Hoàng, Architectural characteristics of the Chinese people in HOQ, Master Thesis, Hanoi Architectural University (2020)

14. M. Nguyen, French townhouses in $H O Q$, Architectural Journal, Vietnam Association of Architects 11,12 (2017). 